\title{
Effect of Extrusion Process Parameters on Textural Properties of Maize-Millet Based Soy Fortified Extruded Product
}

\author{
Chandrahas Sahu* \\ Department of Dairy Engineering, CDSFT, CGKV, Raipur- 492 012, India \\ *Corresponding author
}

Ke y w o r d s
$\begin{aligned} & \text { Barrel temperature, } \\ & \text { crispness, feed } \\ & \text { moisture content, } \\ & \text { hardness, screw } \\ & \text { speed }\end{aligned}$
Article Info
Accepted:
18 May 2020
Available Online:
10 June 2020

\section{A B S T R A C T}

The objective of present research work was to investigate the effect of process parameters viz., barrel temperature, screw speed and feed moisture content on textural properties of extruded product. The extruded products were developed from composite blend comprising of maize, finger millet, defatted soy and elephant foot yam in the proportion of 40:30:20:10 through the use of co-rotating twin screw extruder. The experimental plan was designed by statistical technique of 3 factors 5 levels central composite rotatable design. The textural properties such as hardness and crispness of extruded products were determined and found significantly with process parameters. The values of hardness and crispness varied in the range of 12.43-19.04 $\mathrm{N}$ and 10-25 fractures, respectively for all the experiments. The minimum hardness $12.43 \mathrm{~N}$ and maximum crispness 25 fractures were found with the combination of barrel temperature: $110^{\circ} \mathrm{C}$, screw speed: $301 \mathrm{rpm}$ and feed moisture content: $14 \%(\mathrm{wb}$ ). Maize, finger millet, defatted soy and elephant foot yam may be used as raw material for composite blend in the development of extruded products in food industry to obtain protein rich extruded product. This product can be acceptable by consumers without compromising its textural quality. Process parameters affect the textural as well as sensory quality of the extruded products. Therefore, in this research we attempt to find the textural relationship with the process parameters using a statistical approach.

\section{Introduction}

Extrusion technology combines a series of unit operations which includes mixing, kneading, cooking, shaping, heating, shearing and forming to develop cheaper, uniform and valuable products. It is flexible, environmental friendly, economical, commercial and very powerful technique used to develop directly expanded snacks in the area of food processing. Extrusion is a hightemperature short-time (HTST) process which has instantaneous pressure and thermal action along with mechanical shearing that produces some modifications like starch gelatinization, protein denaturation, inactivation of enzyme and anti-nutritional activity, increased digestibility and organic value of proteins (Singh et al., 2007). The utilization of locally and easily available raw materials in extrusion 
cooking is very powerful practice to fortification of several nutrients in the final products and has potential to utilize byproducts for the development of a novel commercial product.

Maize is the main cereal grain as measured by production but ranks third as a staple food, after wheat and rice in India. It is the affluent sources of carbohydrate, fiber and minerals like potassium, phosphorus, magnesium, calcium, etc. It is one of the starch rich ingredients and used to prepare variety of RTE products through extrusion cooking in ancient times. Maize flour contains about 72 $76.9 \%$ carbohydrates, $6.9-10.5 \%$ protein, 2.9 $3.9 \%$ fat, $6.5-7.3 \%$ total fiber and $0.8-1.7 \%$ ash (US Department of Agriculture, 2013). Finger millet is vital fasten food in the central and eastern part of Africa and also very famous as low sugar food in some parts of India (Rastogi and Joshi, 2015). Finger millet is known for its richness in minerals like calcium, phosphorus, iron, fiber and vitamin contents. By introducing finger millet in our daily diet, calcium and iron deficiency can be overcome. Magnesium in millet can help to diminish the migraine effect as well as heart attack. Millet is gluten-free, non-allergenic and it gives substantial addition to a vegetarian diet. Due to lack of awareness finger millet is rarely consumed in diet. Finger millet is a good source of diet for growing children, expecting womens', old age people and patients. The dietary fiber and mineral content is higher than wheat, rice and fairly well balanced protein in the form of essential amino acids, vitamins, polyphenols and tannins (Devi et al., 2014).

The flour obtained from cake which is byproducts after extraction of oil from soybean in the oil processing industry is defatted soy flour. The incorporation of defatted soy flour for the development of extruded products will reduce the production cost because it is cheaper than other high protein sources. Quality of soy protein is at par to animal protein and lowers the level of cholesterol because it contains less amount of fat. It also contains many minor elements which were considered as anti-nutritional feature have the cancer preventing action. Addition of soy flour can acts as a good source of protein in the blend which is also offering as nutritional, functional and health benefits (Friedman and Brandon, 2001). Elephant foot yam also known as Jimikand is rich in carbohydrate, protein, vitamins, antioxidants, minerals, dietary fiber and calories rich vegetable. It contains minerals like potassium, phosphorus, zinc, manganese and vitamins in abundant (Seth et al., 2015). It improves the function of digestive system through reduction in irregular bowel movements as well as bloating. The heart disease problem and digestive disorders like constipation, piles, etc. are checked by the utilization of jimikand. Its richness in the omega-3 fatty acid can helps in decreasing the level of bad cholesterol and increases good cholesterol level. It also helps in preventing from the unnecessary blood clotting in the body. It enhances the production and formation red blood cells.

Organoleptic quality characteristics such as taste, appearance, colour, body and texture and flavour are most important parameters for consumers' acceptability of food products. Among them, textural property is one of the most important and especially true for snack foods (Bourne, 2002). Hardness and crispness of extruded products correlated inversely to each other and. In the mastication process, the highest force applied to the products which causes to rupture the cellular structure is called hardness and a pinched sound produced is contributed to the crispness. The crisp materials usually generates irregular forcetime deformation curve in the system attached to texture analyzer. 
The crispness of snack depends on the amount of moisture present in the materials. The extruded products available in the market have mostly prepared from cereals such as corn, rice and wheat. These cereals are mostly higher in carbohydrates and fibers and poor in protein, minerals and vitamins.

Therefore, it is necessary to enhance the values of protein, minerals and vitamins to extruded products to full fill the consumers' nutritional requirements. The aim of present research work is to study the effect of process parameters on textural properties of extruded product made from composite blend of maizefinger millet with the fortification of defatted soy and elephant foot yam.

\section{Materials and Methods}

\section{Raw materials}

Maize, finger millet, defatted soy and elephant foot yam (YP) were taken as raw materials for development of extruded product. Maize, finger millet and elephant foot yam were procured from the Shaheed Gundadhur College of Agriculture and Research Station, Jagdalpur (CG). Defatted soy was procured from Bhatnagar Industries Ltd., Bhopal (MP). Cleaned and dried maize and finger millet were converted into flour using a small capacity commercial pulveriser.

Small cubes of elephant foot yam were boiled in pressure cooker for 15-20 minutes to enable peeling of the outer skin easily. After peeling, the cubes were further cut into small pieces to facilitate faster and easy drying. These pieces were dried to nearly $10 \%$ moisture content at $70^{\circ} \mathrm{C}$ using a tray dryer and then cooled and converted into powder using commercial pulveriser. The flour samples were filled in re-sealable air tight low density polyethylene (LDPE) pouches and kept in a cool and dry place until use.

\section{Extrusion cooking}

The composite blend (maize: $40 \%$, finger millet: $30 \%$, defatted soy: $20 \%$ and elephant foot yam: 10\%) was employed for the production of extruded product. The extruded product was developed using a co-rotating twin-screw extruder (Lab model, BTPL, Kolkata, India).

The diameter of the die $3 \mathrm{~mm}$, feed rate 24 rpm and cutter speed $22 \mathrm{rpm}$ were kept constant during the entire study. The extruder was performed at five different level of barrel temperature and screw speed for development of product. Extruded products were allowed to cool at room temperature and packed into zip lock LDPE pouch until further investigation of hardness and crispness by texture analyzer.

\section{Design of experiment and data analysis}

Response surface methodology (RSM) was adopted in experimental design combinations. The mathematical and statistical techniques are combined to develop functional relationship between independent variables and their associated dependent variable (responses) is called RSM. The central composite rotatable design (CCRD) for three independent variables viz. barrel temperature, screw speed and feed moisture content was used. Based on preliminary trial and literatures information, level of each independent variable was selected for the development of extruded products which is shown in Table 1.

A second-order polynomial regression model for the dependent variable was established to fit the experimental data for each response as per Equation (1):

$y_{i}=\beta_{0}+\sum_{i=1}^{3} \beta_{i} x_{i}+\sum_{i=1}^{3} \beta_{i i} x_{i}^{2}+\sum_{i=1}^{2} \sum_{j=i+1}^{3} \beta_{i j} x_{i} x_{j}$ 
Where $x_{\mathrm{i}}, x_{\mathrm{i}}^{2}, x_{\mathrm{i}} x_{\mathrm{j}}$ are linear, quadratic and interaction terms of the input variables respectively, which influence the responses y and $\beta_{0}, \beta_{\mathrm{i}}$ and $\beta_{\mathrm{ij}}$ are the regression coefficients.

The adequacy of the developed models and significance of the model terms were determined by regression analysis of variance (ANOVA). The response surface plots and statistical analysis was carried out using Design Expert software (version 10.0.5.0).

\section{Textural properties evaluation}

Texture analyzer is a mechanical device used for finding the physical properties of food products with the help of different sets of probe and fixture. The textural characteristics of extruded product was measured by the application of TA-HD plus texture analyzer (Stable micro system, Texture Technology corp., UK) with a specified attachment provided for similar products, crisp fracture rig and $\mathrm{P} / 0.25$ probe (Figure 1).

The test was conducted at a pretest speed of $1.0 \mathrm{~mm} / \mathrm{s}$, test speed of $1.0 \mathrm{~mm} / \mathrm{s}$, posttest speed of $10 \mathrm{~mm} / \mathrm{s}$, distance of travel $5 \mathrm{~mm}$, data acquisition rate of $400 \mathrm{pps}$ and load cell of $50 \mathrm{~kg}$. Hardness is the highest positive peak force during first rupture or penetration of the product which is expressed in Newton (Pawar et al., 2014).

Exponent Lite software, version 6.1.11.0 was used to evaluate the textural properties of the sample. In order to determine the hardness of extruded products sample piece was put on the top of the platform in texture analyzer. Crispness was obtained by counting the number of positive peaks (fractures) recorded in force-time deformation curve in the Exponent Lite software. The data and its plot were acquired and drawn automatically by texture analyzer which was attached into PC.

\section{Results and Discussion}

\section{Hardness}

Hardness is linked with the expansion and cell arrangement of the product. Table 2 showed that hardness values of extruded products were found to be changed from $12.43-19.04$ $\mathrm{N}$. The extruded samples prepared with the combination of process parameters $110^{\circ} \mathrm{C}$ barrel temperature, $301 \mathrm{rpm}$ screw speed and $14 \%$ (wb) feed moisture content demonstrated the minimum hardness value $12.43 \mathrm{~N}$ whereas the maximum value $19.04 \mathrm{~N}$ was obtained with the combination of barrel temperature $110^{\circ} \mathrm{C}$, screw speed $159 \mathrm{rpm}$ and feed moisture $18 \%$ (wb).

Hardness of extruded products had found to be affected significantly by the process parameters at $0.1 \%$ level of significance (Table 3). Among the interaction terms only barrel temperature-feed moisture content $\left(x_{1} x_{3}\right)$ had significantly affected the process and hardness. The effect of process parameters on hardness can be explained effectively by two factor interaction (2FI) model.

The model with high F-value is highly significant $(\mathrm{p}<0.001)$ with non-significant lack-of-fit. Additionally, high value of coefficient of determination $\left(\mathrm{R}^{2}=0.92\right)$ suggests its closeness in describing the relationship.

The predicted $\mathrm{R}^{2}(0.72)$ was in agreement with the adjusted $\mathrm{R}^{2}(0.88)$ which further supports its adequacy. A high adequate precision ratio (18.14) along with low CV $(4.31 \%)$ indicated that model is well within the acceptable level for the range of variables. The model to predict hardness of extruded product after neglecting the non-significant terms in terms of coded value of independent variables is given in Equation (2): 
$\mathrm{H}=15.10-0.88 x_{1}-0.98 x_{2}+1.32 x_{3}-0.071$

$x_{1} x_{2}-1.26 x_{1} x_{3}-0.00125 x_{2} x_{3}$

$\mathrm{R}^{2}=0.92$

It is clear from the Equation (2) that highest positive coefficient of feed moisture content had highest positive influence on hardness whereas screw speed and barrel temperature had negatively affected. This means that the increase in feed moisture content on the product increased the hardness but hardness decreased with the increase in barrel temperature and screw speed.

Hardness increased with the increase in feed moisture content, which may be due to reduced expansion, increased product density and slower gelatinization of starch (Figure 2). Similar types of findings were also been found for development of wheat based expanded snacks (Ding et al., 2006) and yamcorn-rice based extruded snack food (Seth $e t$ al., 2015).

Hardness of extruded products decreased with the increase in barrel temperature which is in agreement with the result of health promising extrudate developed from composite blend of fenugreek, oat and pea (Wani and Kumar, 2016).

Increase in barrel temperature leads to expansion of extruded products which may be because of reduced melt viscosity and faster release superheated steam produces more numbers of bubble in the product (Figure 3). Figure 4 depicts that increased screw speed leads to decrease the hardness of extruded product, which can be due to disruption of the material with the growth of high mechanical shear by the release of superheated steam before leaving the die. Similar results have also been observed for corn-barley based extrudates (Altan et al., 2008) and for chickpea flour based extruded product (Meng et al., 2010).

\section{Crispness}

One of the most important textural properties of extruded product is crispness which indicates the pitched sound occur during mastication of products. High crisp product is desirable by the consumers' as it imparts soothing palatability. The numbers of positive peaks produced during fracture of products in force-time deformation curve through texture analyzer is known as crispness and its values varied from 10-25 fractures for all the experiments (Table 2). Regression analysis was done to understand the effect of process variables on crispness and presented in the form of ANOVA in Table 4. It can be seen that the linear terms of screw speed $\left(x_{2}\right)$ and feed moisture content $\left(x_{3}\right)$ had significantly affected the crispness at $1 \%$ level while barrel temperature $\left(x_{1}\right)$ had emerged as the nonsignificant factor. Among the interaction terms only temperature-feed moisture $\left(x_{1} x_{3}\right)$ had significantly affected the process. The analysis further revealed that the crispness was adequately explained by two factor interaction (2FI) model. This model was found to be significant at $1 \%$ level with high F-value (7.09). A high value of coefficient of determination $\left(\mathrm{R}^{2}=0.77\right)$ for the model along with its predicted $R^{2}$ value $(0.50)$ which was in agreement with the adjusted $R^{2}(0.66)$ further shows the adequacy of the relationship. The regression equation in terms of coded values of variables representing the variation of crispness of the extruded products is given below (Equation 3):

$\mathrm{Cr}=17.50+0.69 x_{1}+2.16 x_{2}-1.93 x_{3}-0.75$ $x_{1} x_{2}+2.50 x_{1} x_{3}-0.75 x_{2} x_{3}$

$\mathrm{R}^{2}=0.77$

The above Equation (3) showed that the highest positive contribution on crispness was obtained by $x_{2}$ which hold highest positive coefficient (2.16) followed by $x_{1}$ whereas negatively affected by $x_{3}$. 
Table.1 Coded value of process parameters used in central composite rotatable design

\begin{tabular}{|c|c|c|c|c|c|c|}
\hline \multirow[t]{2}{*}{ Process parameters } & \multirow{2}{*}{ Coded } & \multicolumn{5}{|c|}{ Levels } \\
\hline & & $-\alpha(-1.68)$ & -1 & $\mathbf{0}$ & +1 & $+\alpha(+1.68)$ \\
\hline Barrel temperature, ${ }^{\circ} \mathrm{C}$ & $x_{1}$ & 100 & 110 & 125 & 140 & 150 \\
\hline Screw speed, rpm & $x_{2}$ & 110 & 159 & 230 & 301 & 350 \\
\hline $\begin{array}{l}\text { Feed moisture content, \% } \\
\text { (wb) }\end{array}$ & $x_{3}$ & 12 & 14 & 16 & 18 & 20 \\
\hline
\end{tabular}

Table.2 Central composite rotatable design with process variables and experimental results of extruded products

\begin{tabular}{|c|c|c|c|c|c|}
\hline Run No. & $\begin{array}{c}\text { Barrel } \\
\text { temperature }\end{array}$ & Screw speed & $\begin{array}{l}\text { Feed moisture } \\
\text { content }\end{array}$ & Hardness & Crispness \\
\hline & ${ }^{\circ} \mathrm{C}$ & rpm & $\%$ wb & $\mathbf{N}$ & \\
\hline 1 & 125 & 230 & 12 & 13.39 & 17 \\
\hline 2 & 150 & 230 & 16 & 14.05 & 16 \\
\hline 3 & 125 & 230 & 16 & 15.34 & 19 \\
\hline 4 & 125 & 230 & 16 & 14.98 & 20 \\
\hline 5 & 125 & 110 & 16 & 17.25 & 14 \\
\hline 6 & 140 & 159 & 18 & 14.80 & 19 \\
\hline 7 & 140 & 159 & 14 & 15.13 & 16 \\
\hline 8 & 100 & 230 & 16 & 17.81 & 14 \\
\hline 9 & 125 & 350 & 16 & 13.09 & 22 \\
\hline 10 & 125 & 230 & 16 & 15.72 & 16 \\
\hline 11 & 140 & 301 & 18 & 13.47 & 19 \\
\hline 12 & 125 & 230 & 20 & 17.86 & 12 \\
\hline 13 & 110 & 159 & 18 & 19.04 & 10 \\
\hline 14 & 125 & 230 & 16 & 14.33 & 18 \\
\hline 15 & 140 & 301 & 14 & 12.95 & 21 \\
\hline 16 & 125 & 230 & 16 & 15.26 & 20 \\
\hline 17 & 125 & 230 & 16 & 14.58 & 18 \\
\hline 18 & 110 & 301 & 14 & 12.43 & 25 \\
\hline 19 & 110 & 159 & 14 & 13.47 & 19 \\
\hline 20 & 110 & 301 & 18 & 17.14 & 15 \\
\hline
\end{tabular}


Table.3 Analysis of variance (ANOVA) showing the effect of process parameter on hardness of extruded products

\begin{tabular}{|c|c|c|c|c|c|}
\hline Source & $\begin{array}{l}\text { Sum of } \\
\text { Square }\end{array}$ & df & $\begin{array}{l}\text { Mean } \\
\text { Square }\end{array}$ & F value & $\begin{array}{c}\text { p-value } \\
(\text { Prob }>\text { F })\end{array}$ \\
\hline Model & 60.34 & 6 & 10.06 & 23.76 & $<0.0001 * * *$ \\
\hline$x_{1}$ - Temperature & 10.64 & 1 & 10.64 & 25.14 & $0.0002 * * *$ \\
\hline$x_{2}-$ Screw speed & 13.24 & 1 & 13.24 & 31.28 & $<0.0001 * * *$ \\
\hline$x_{3}-$ Moisture content & 23.69 & 1 & 23.69 & 55.98 & $<0.0001^{* * *}$ \\
\hline$x_{1} x_{2}$ & 0.041 & 1 & 0.041 & 0.096 & $0.7616^{\mathrm{ns}}$ \\
\hline$x_{1} x_{3}$ & 12.73 & 1 & 12.73 & 30.07 & $0.0001 * * *$ \\
\hline$x_{2} x_{3}$ & 0.0000125 & 1 & 0.0000125 & 0.0000295 & $0.9957^{\mathrm{ns}}$ \\
\hline Residual & 5.50 & 13 & 0.42 & & \\
\hline Lack of Fit & 4.18 & 8 & 0.52 & 1.98 & $0.2343^{\mathrm{ns}}$ \\
\hline Pure Error & 1.32 & 5 & 0.26 & & \\
\hline $\mathbf{R}^{2}$ & 0.92 & & & & \\
\hline Adjusted $\mathbf{R}^{2}$ & 0.88 & & & & \\
\hline Predicted $\mathbf{R}^{2}$ & 0.72 & & & & \\
\hline APR & 18.14 & & & & \\
\hline $\mathrm{CV}(\%)$ & 4.31 & & & & \\
\hline
\end{tabular}

Table.4 Analysis of variance (ANOVA) for the effect of extrusion process variables on crispiness of extruded products

\begin{tabular}{|l|c|c|c|c|c|}
\hline Source & $\begin{array}{c}\text { Sum of } \\
\text { Square }\end{array}$ & df & $\begin{array}{c}\text { Mean } \\
\text { Square }\end{array}$ & F value & $\begin{array}{c}\text { p-value } \\
\text { (Prob>F) }\end{array}$ \\
\hline Model & 180.01 & 6 & 30.00 & 7.09 & $<0.0016^{* *}$ \\
\hline $\boldsymbol{x}_{\mathbf{1}}$ - Temperature & 6.42 & 1 & 6.42 & 1.52 & $0.2398^{\text {ns }}$ \\
\hline $\boldsymbol{x}_{\mathbf{2}}$ - Screw speed & 63.53 & 1 & 63.53 & 15.02 & $0.0019^{* *}$ \\
\hline $\boldsymbol{x}_{\mathbf{3}}$ - Moisture content & 51.07 & 1 & 51.07 & 12.07 & $0.0041^{* *}$ \\
\hline $\boldsymbol{x}_{\mathbf{1}} \boldsymbol{x}_{\mathbf{2}}$ & 4.50 & 1 & 4.50 & 1.06 & $0.3211^{\mathrm{ns}}$ \\
\hline $\boldsymbol{x}_{\mathbf{1}} \boldsymbol{x}_{\mathbf{3}}$ & 50.00 & 1 & 50.00 & 11.82 & $0.0044^{* *}$ \\
\hline $\boldsymbol{x}_{\mathbf{2}} \boldsymbol{x}_{\mathbf{3}}$ & 4.50 & 1 & 4.50 & 1.06 & $0.3211^{\mathrm{ns}}$ \\
\hline Residual & 54.99 & 13 & 4.23 & & \\
\hline Lack of Fit & 43.49 & 8 & 5.44 & 2.36 & $0.1792^{\mathrm{ns}}$ \\
\hline Pure Error & 11.50 & 5 & 2.30 & & \\
\hline $\mathbf{R}^{\mathbf{2}}$ & 0.77 & & & & \\
\hline Adjusted R & 0.66 & & & & \\
\hline Predicted R & 0.50 & & & & \\
\hline APR & 12.07 & & & & \\
\hline CV $(\boldsymbol{\%})$ & 11.75 & & & & \\
\hline
\end{tabular}

$* * \mathrm{p}<0.01, * \mathrm{p}<0.05, \mathrm{~ns}-$ Non-significant 


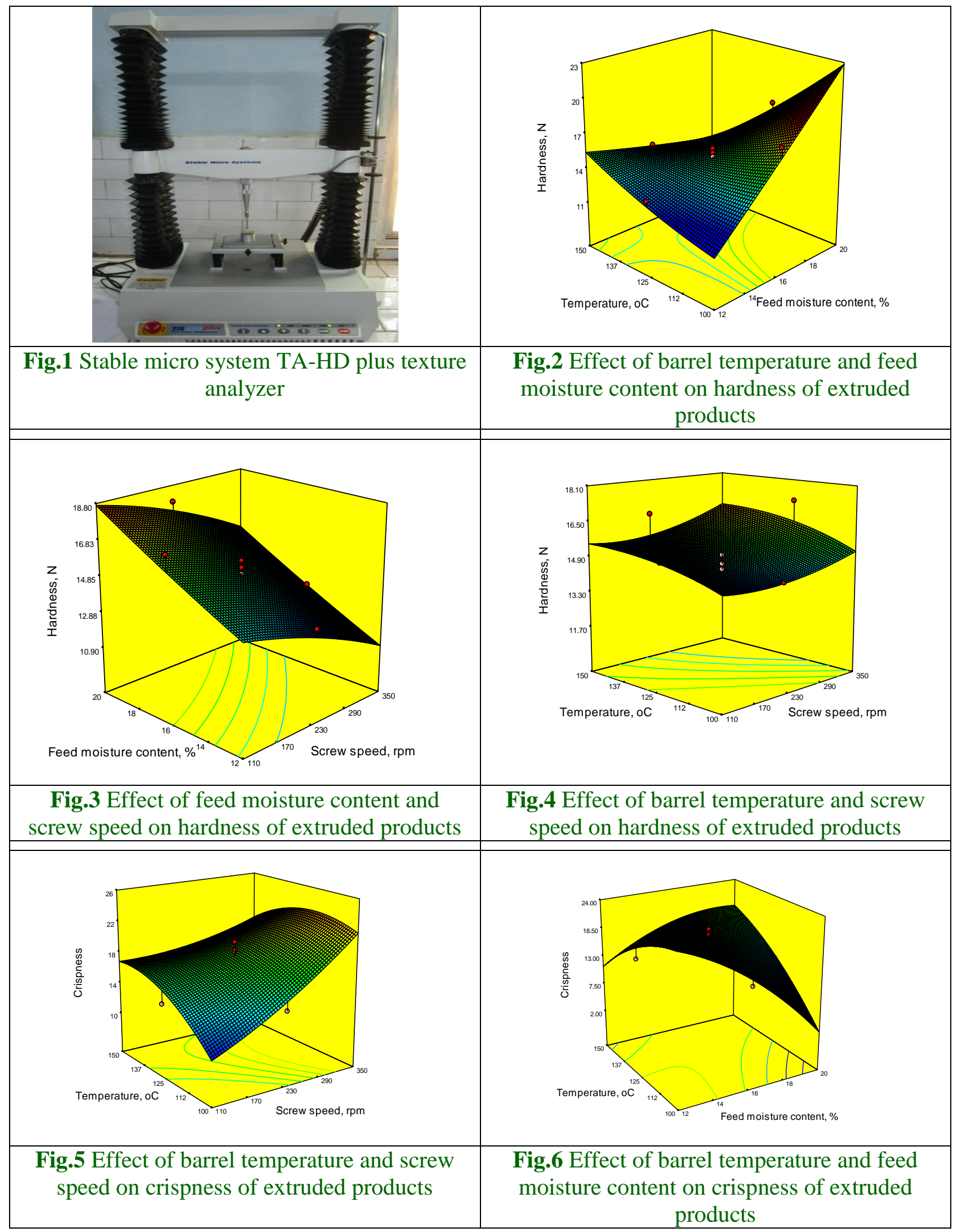


This means that the increase in barrel temperature and screw speed increased the crispness whereas decreased by the increase in moisture content. 3-D surface graph (Figure 5) also described that the crispness increased with the increase in barrel temperature and screw speed during extrusion.

The increase in crispness with the increase in barrel temperature might be due to more evaporation of moisture, decreased melt viscosity and formation of more porous structure of extruded products. The increase in barrel temperature is helpful in increasing the bubble radius along with increase in matrix radius causing the reduction in thickness of shell wall, which yields a product with poor structure and more number of fractures while testing for compression (Wang et al., 2005). Also with the increase in screw speed the crispness increased, which may be due to development of enhanced mechanical shearing of melts inside the barrel causes formation of continuous foam and product containing comparatively more bubbles responsible for the pore spaces. Similar results have been found by Ding et al., (2006) for development of rice-based expanded snacks.

The negative coefficient of feed moisture content had influenced negatively on crispness, which produces bulky extruded products with poor expansion. Figure 6 depicted that crispness decreased with the increase in feed moisture content of the blend. This may be due to reduction in elasticity of the dough during plasticization of melt which is responsible for production of compact and bulky products. The high moisture may reduce the bubble growth thereby reducing the crispiness values. The results have also been supported with previous findings by Azam et al., (2016) in the kodo based soy fortified RTE extruded snacks.
In conclusion, the textural properties of extruded products developed from maizefinger millet based soy fortified blend using twin-screw extruder were significantly affected by extrusion process variables. The moisture content of the feed blend had positive effect on hardness whereas negatively affected on crispness of extruded products. Barrel temperature and screw speed of extruder had positive effect on crispness and negative effect on hardness of products. The value hardness and crispness varied in the range of 12.43-19.04 $\mathrm{N}$ and 10-25 fractures, respectively. The minimum hardness $12.43 \mathrm{~N}$ and maximum crispness 25 fractures of extruded product had found in the combination of process variables, barrel temperature: $110^{\circ} \mathrm{C}$, screw speed: $301 \mathrm{rpm}$ and feed moisture content: $14 \%$ (wb).

\section{References}

Altan, A., McCarthy, K. L. and Maskan, M. 2008. Evaluation of snack foods from barley-tomato pomace blends by extrusion processing. Journal of Food Engineering. 84(2): 231-242.

Azam, M., Singh, M. and Verma, D. K. 2016. Textural properties of kodo (Paspalum scrobiculatum L.) based soy fortified ready to eat extruded snacks using response surface methodology. Indian Journal of Science and Technology. 9(4): 1-5.

Bourne M. C. 2002. Food texture and viscosity: Concept and measurement. Academic Press Inc., USA.

Devi, P. B., Vijayabharthi, R., Satyabhama, S., Malleshi, N. G. and Priyadarisini, V. B. 2014. Health benefits of finger millet (Eleusine coracona L.) polyphenols and dietary fiber: A review. Journal of Food Science and Technology. 51(6): 10211040.

Ding, Q. B., Ainsworth, P., Plunkett, A., Tucker, G. and Marson, H. 2006. The 
Effect of extrusion conditions on the functional and physical properties of wheat-based expanded snacks. Journal of Food Engineering. 73(2): 142-148.

Friedman, M. and Brandon, D. L. 2001. Nutritional and health benefits of soy proteins. Journal of Agriculture and Food Chemistry. 49(3): 1069-1086.

Meng, X., Threinen, D., Hansen, M. and Driedger, D. 2010. Effects of extrusion conditions on system parameters and physical properties of a chickpea flour based snack. Food Research International. 43(2): 650-658.

Pawar, S. G., Pardeshi, I. L., Borkar, P. A. and Rajput, M. R. 2014. Optimization of process parameters of microwave puffed sorghum based ready-to-eat (RTE) food. Journal of Ready to Eat Food. 1(2): 59-68.

Rastogi, M. and Joshi, M. 2015. Effect of ragi (Eleusine Coracana) for the development of value added products and their nutritional implication. Asian Journal of Home Science. 10(1): 1-5.

Seth, D., Badwaik, L. S. and Ganapathy, V. 2015. Effect of feed composition, moisture content and extrusion temperature on extrudate characteristics of yam-corn-rice based snack food. Journal of Food Science and Technology. 52(3): 1830-1838.

Singh, S., Gamlath, S. and Wakeling, L. 2007. Nutritional aspects of food extrusion: A review. International Journal of Food Science and Technology. 42(8), 916929.

USDA. 2013. United States Department of Agriculture. USDA National Nutrient Database for Standard Reference, Release 25. Nutrient Data Laboratory Home page. Accessed April 6, http://www.ars.Usda.gov/ba/bhnrc/ndl.

Wang, L., Ganjyal, G. M., Jones, D. D., Weller, C. L. and Hanna, M. A. 2005. Modeling of bubble growth dynamics and nonisothermal expansion in starchbased foams during extrusion. Advances in Polymer Technology. 24(1): 29-45.

Wani, S. A. and Kumar, P. 2016. Development and parameter optimization of health promising extrudate based on fenugreek, oat and pea. Food Bioscience. 14(1): 34-40.

\section{How to cite this article:}

Chandrahas Sahu. 2020. Effect of Extrusion Process Parameters on Textural Properties of Maize-Millet Based Soy Fortified Extruded Product. Int.J.Curr.Microbiol.App.Sci. 9(06): 2098-2107. doi: https://doi.org/10.20546/ijcmas.2020.906.257 